\title{
Supply chain emerging aspects and future directions in the age of COVID-19: A systematic review
}

\author{
Omar Alhawari ${ }^{a^{*}, \text { Khurrum Bhutta }^{\mathrm{a}} \text { and Asif Muzzafar }}{ }^{\mathrm{b}}$
}

${ }^{a}$ Ohio university, United States

${ }^{b}$ University of Technology and Applied Sciences, Oman

\begin{tabular}{l}
\hline C H R O N I C L E \\
\hline Article history: \\
Received October 28,2020 \\
Received in revised format \\
January, 15,2021 \\
Accepted January 302021 \\
Available online \\
January 302021 \\
\hline Keywords: \\
Supply chain management \\
Sustainability \\
Viability \\
Supply chain disruptions \\
Supply chain resilience \\
COVID-19
\end{tabular}

\section{A B S T R A C T}

\begin{abstract}
Not only has the COVID-19 outbreak brought about public safety challenges, but there has also been a major disruption in the business world that impacts one and all from small to large businesses. During This pandemic, supply chains (SCs) have witnessed disruptions, and this has inspired the interest of this paper. Therefore, the objective of the paper is to address two research questions pertaining to exploring the emerging SC aspects in the age of COVID-19 and future directions of SCs. To achieve this objective, a methodology is developed entailing three steps as follows. First, data is collected and included documents are identified through PRISMA strategy. Second, document analytics is performed using the web-interface of bibliometrix package in $\mathrm{R}$ software,the shiny app. Third, the research questions are addressed accordingly. The results showed that the most prominent terms related to SCs include supply chain disruptions, supply chain management,supply chain resilience, viability, and flexibility. Consequently, the first research question is approached in which the aspects of SC disruptions, resilient SC, viable SC, Sustainable SC, and SC management, are addressed. With more focus on building resilient $\mathrm{SC}$ in the short-term to recover from disruptions, viable $\mathrm{SC}$ can be created in the long-term perspective, which eventually build sustainable SC accordingly. Subsequently, considering these aspects enable successful SC management. Additionally, the future directions are explored including the transformation from globalization to regionalization perspective, focus on digitalization, need for holding more inventory, managing SCs for high resilience, more dependence on operations research and business analytics, and reconsideration of food SCs. This paper contributes to the body of knowledge by providing insightful research agenda to scholars and practitioners concerned in exploring more of the influences of the current pandemic on SCs.
\end{abstract}

\section{Introduction}

Business corporations build their supply chains (SCs) to achieve goals in their markets and satisfy customers accordingly. This has enforced a great pressure on the way they compete with their rivals locally and globally. In SCs, companies compete to meet customer requirements by increasing their operational competencies (Alhawari et al., 2020). SCs are considered as the lifeblood of economies and society (Ivanov, 2020a). Stevenson (2018) mentioned that companies (e.g., suppliers, manufacturers, warehouses, retailers) are connected to perform the associated roles to construct a sequence starting from the point of getting raw materials and turn them into finished products to be delivered to the point of consumption. The movement of products, materials, equipment, etc. through SC is known as logistics and requires various ways of transportation such as planes, automobiles, ships, etc. There are a set of activities of operations across SCs including obtaining raw material, making finished products, handling inventory, demand estimating, managing information, controlling quality of inbound and outbound items, scheduling workers and machines, distributing of products and serving customers. According to Beamon (1998), Fig. 1 shows that SC consists of two combined processes: the process of the

* Corresponding author

E-mail address: alhawari@ohio.edu (O. Alhawari)

C 2021 by the authors; licensee Growing Science. doi: $10.5267 /$ j.uscm.2021.1.007 
production planning and inventory control and the process of distribution and logistics. The production planning refers to design and management decisions of the whole manufacturing process, whereas inventory control considers the design and management of storing materials, semi-finished and finished goods. Additionally, the process of distribution and logistics describes the goods delivery decisions and policies.

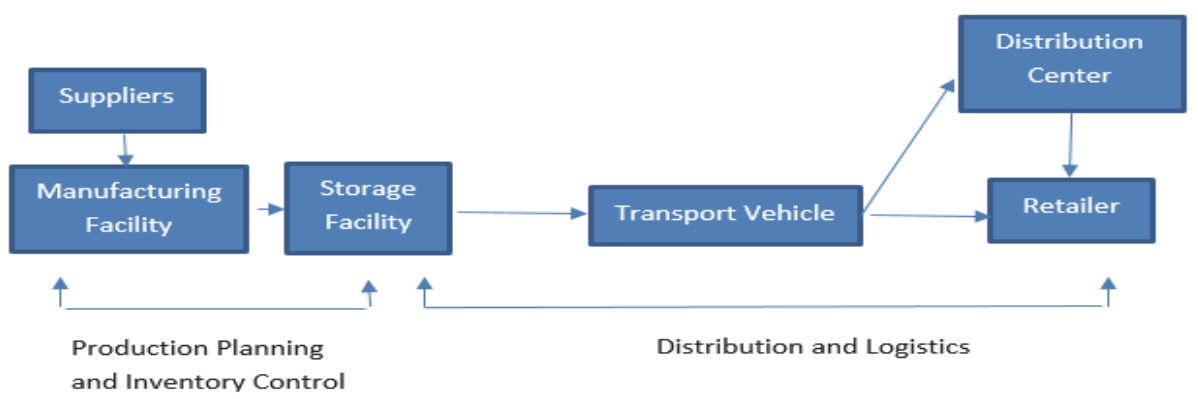

Fig. 1. SC processes (adapted from Beamon, 1998)

Some of the issues related to SCs such as management, globalization, design, and risks are addressed.

\subsection{SC Management and Globalization}

SC management does not only consider operational decisions, but also strategic decisions within and beyond the business(Ganeshan et al., 1999). Also, SC management is defined as the integration of functions by companies or facilities who are in charge for getting raw materials, converting them into final products and supplying them to customers through possible delivery methods (Lee \& Billington, 1995). The strategic and effective harmonization between businesses or companies, participating in SCs, has been essential to integrate the management of supply. Managing SCs is needed so that companies can enhance the performance of their operations, improve digital-business environment, control and manage inventories, recognize competitive pressure, etc. (Stevenson, 2018). Effective SCs require managing the three flows occurring along the chain including the material and service, information, and financial types. In the global perspective, SC is lengthened to include companies across the world. For instance, suppliers, manufacturers, and final consumers might be present in different continents or countries. The need for global supply chains emerges from opening non-domestic markets and selling products globally. Further, the availability and cost of the raw materials and workers might be beneficial to businesses globally. Global supply chains influence businesses' strategies due to the intensified challenges including lengthier lead times (the time difference between placing an order until receiving an order), bouncing wage areas, fluctuating currencies, varying cultures and languages, and governments' controls. Besides, higher transportation costs, delayed deliveries, faulty quality standards, etc. AS a result of the increase in globalization levels, Meixell \& Gargeya (2005) stated that supply chains exceed local market to reach out global boundaries and enforce difficulties on supply chain managers.

\subsection{SC Network Design and Decision Making}

SC network design describes how the many functions and activities, implemented by a variety of organizations, are integrated to achieve SC goals. Erenay (2016) indicated that SC managers should realize the issue of design considering aspects such as locations of prospective consumers, available suppliers, labor rates, transportation expenses, etc. Besides, SC designers take into consideration the boundaries of the numbers, locations and capacities of the facilities including plants/producers, warehouses, and distribution centers. Design decisions are also made on shipping aspects of goods considering quantities and delivery modes. The design of SC network considers performance measures with objectives such as total cost minimization, total profits maximization, etc. In a recent environment where the businesses try to keep the change pace as much as possible, the design matter should be accommodating and flexible to react swiftly to any occurring changes (e.g., social, environmental, weather issues, etc.).

Furthermore, SC networking involves strategic, tactical, and operational decisions that are made across SC members. In regard to strategic decisions, according to (Lambiase et al.,2013) pointed out that these types of decisions are made for long-duration commitments and usually made by higher management levels. Some decisions include firm location, capacity management, process selection, and include technology selection, capacity, sourcing, pricing policies and facility location. Klibi et al., (2010) indicated some strategic issues that should be considered in SC networking design such as the targeted markets, pricing, manufacturers' location and distribution centers, technology embracing, product design, capacity planning, supplier choice, etc. The tactical decisions are made for short-duration commitment for activities on a weekly or monthly basis and made by the middle manager considering distribution management, inventory management, production planning, forecasting, etc. (Wisner, 2016; Stevenson, 2018; Erenay, 2016). Lastly, operational decisions level is considered for day-to-day operations and made by operational managers including activities such as scheduling, sequencing, production management, vehicle routing decisions, etc. (Wisner, 2016; Stevenson, 2018). 


\subsection{SC Risk and Uncertainty}

SCs normally encounter changing demands in terms of stochasticity and seasonality nature. This causes challenges on capacity, production, inventory level, manufacturing system design, etc. In SCs, layouts of manufacturing systems are designed and assessed considering the stochastic nature of market demand (Alhawari \& Suer, 2019). Van der Vorst \& Beulens (2002) indicated that SC uncertainty enforces distortions and lacks information to achieve to implement activities and achieve activities. In other words, decision makers are under pressure to figure out the SC behaviors and conditions to be able to effectively control SCs. The two terms, uncertainty and risk in SC, are used conversely; however, there is an insignificant distinction as risk can be characterized as the likelihood of occurrence of a specified magnitude of the occurrence (Zsidisin, 2003). The likelihood is recognized for the risk unlike uncertainty. For illustration, a supplier's risk is the likelihood that an event related to inbound shipment from a supplier happens where its consequences result in unfulfilling customer necessities by the buying business (Siegel, 2005). SC risks are comprehensive and grouped into operational and disruption risks (Choi et al., 2019, Xu et al., 2020). The operational risks are associated with daily interruptions in SC operations including lead time and demand variations, whereas the disruption risks are appropriate in what so called low-frequency-high-impact occurrences (Kinra et al., 2020). The disruption risks are in the forms of natural disasters such as upheavals, earthquakes and tsunami, terrorism attacks, strikes, pandemic outbreaks, etc. (Ivanov et al., 2019). Such risks are considered to have a very powerful and instant impact on the formation and configuration of SC network design as some manufacturers, suppliers, distribution center and logistics resources turn out to be temporarily inaccessible. According to (Dolgui et al., 2020; Li \& Zobel, 2020), the product and raw materials shortages and distribution delays, proliferate downstream the SC, result in the situation of the ripple effect and lower the performance of service level efficiency; hence, profits are affected negatively. Currently, the whole globe is suffering from the epidemic outbreak of COVID-19. This outbreak is unique and distinct from other risks that start insignificant then expand rapidly and scatter over many geographic territories.

The structure of this paper is organized as follows. Section 1 discusses the introduction. Section 2 considers COVID-19 pandemic and impacted SCs. Section 3 shows the research methodology. Section 4 addresses the research question of this paper and Section 5 provides the conclusions and future work.

\section{COVID-19 Pandemic and Impacted SCs}

In December 2019, the current coronavirus (COVID-19/SARS-CoV-2) outbreak is originated in Wuhan area, China as shown in Figure 2. Wuhan city is an economically vital for global trade and serves as a main transportation hub for importers and exporters Afterwards, it was confirmed as a global contagion by the WHO on March 11th, 2020 (Ivanov, 2020b; Sharma et al., 2020, Pasuluri et al., 2020; Ivanov \& Dolgui,2020; Fonseca \& Azevedo, 2020). It instantly crushed Chinese exports and considerably decreased the supply readiness in global SCs where market demand is extremely impacted. Araz et al., (2020) emphasized that the COVID-19 epidemic is considered one of the foremost disruptions combatted during the last decades as global SCs are ripped off. Moreover, the characteristics of COVID-19 distinguish it from preceding catastrophes in terms of the geographic scale of the impact, and the effect on supply and demand (Kwon, 2020)

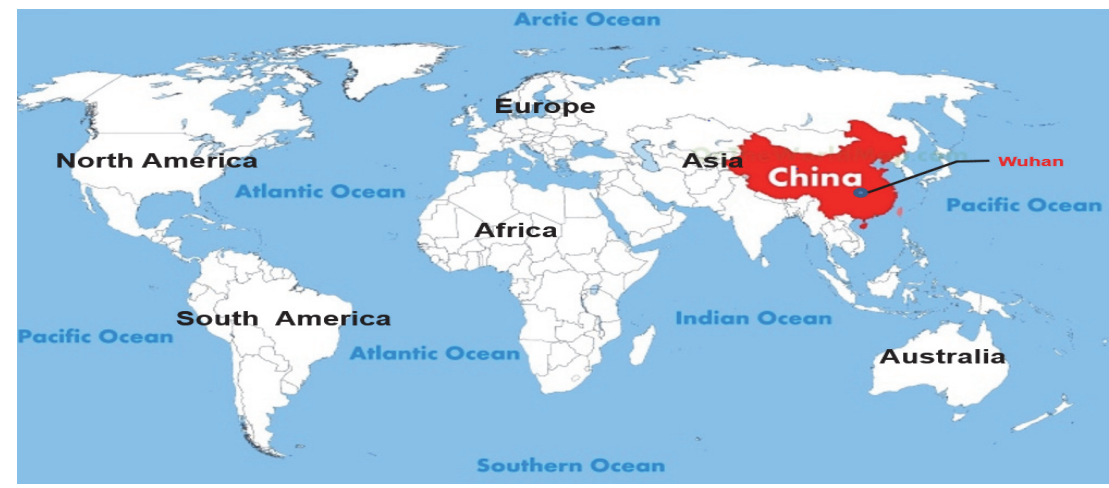

Fig. 2. Wuhan city, China (adapted from worldmap.com)

Countries have imposed travel bans, border controls, and export restrictions on food commodities (Sharma et al., 2020). Therefore, this pandemic has caused disruptions to SCs locally and globally. According to (Klibi et al., 2010), SC network entails five bodies: external suppliers organizations, manufacturing organizations, distribution centers, demand areas or zones and transportation resources. These bodies have been affected by the COVID-19 outbreak. The spread of this virus has been incredibly vast as it has reached almost the entire geographic regions in the world (Ivanov \& Dolgui, 2020a). According to (Ivanov, 2020a), the pandemic has obstructed the Chinese exports resulting in great blockage of so many SCs across the globe. The literature works indicated that 51,000 firms throughout the world have one or more tier-one 
providers/suppliers in Wuhan and a minimum of five million firms across the world, have one or more tier-two providers/suppliers in the Wuhan area, the COVID-19's source (Dun \& Bradstreet, 2020; Paul \& Chowdhury, 2020). Additionally, the authors stated that Wuhan area entails suppliers of around 938 of the Fortune 1000 firms as $94 \%$ of the firms are considered as COVID-19-driven SC disruptions. The risen number of COVID-19 cases has caused border closings, quarantines, and shutdowns of many critical resources, functions, and markets in the local and global SCs (Ivanov \& Dolgui, 2020a). The world's biggest and leading 1000 SCs hold at least 12,000 facilities in coronavirus quarantine zones (Linton \& Vakil, 2020, Ivanov, 2020b).

Global SCs were obliged to respond rapidly, when COVID-19 began to race through China. The immediate challenge caused by COVID-19 was that it broke most transportation and distribution methods throughout the entire SC. With most of the global SCs' raw materials coming from the Asian side, the total lockdown due to COVID-19 caused massive supply disruption and shortages around the globe (Kumar, et al., 2020). In addition to creating supply shortages in the earlier times, COVID-19 also increased demand for many of the already disrupted products due to fear of lengthy shortages such as toilet paper and isopropyl alcohol. This increase in demand created a bullwhip effect which was especially pronounced when combined with the concurrent supply shocks due to lockdowns and halting production. Medical items like PPE equipment and ventilators were especially affected, but many industries suffered from similarly ill-timed bullwhip effects (Patrinley, et al., 2020). During the earlier stages of COVID-19 when there was no complete and authoritative treatment for this transmittable disease, some industries including pharmaceutical manufacturing were supporting governments to meet the needs resulting by COVID-19. According to (Ayati et al, 2020), COVID-19 has affected the pharmaceutical industries through increasing the demand for medical supplies (e.g., health appliances, vaccines, etc.) and supply deficiencies. Therefore, this support is in terms of research and development measures on the possibility of reaching effective treatment strategies to stabilize medical SCs in the time of this catastrophe. Additionally, the mitigating measures taken by governments to respond to the terrible spread of COVID-19 such as physical distancing, closures, lockdowns, etc. have negative impacts on SCs. For instance, in the earlier times of this pandemic, the disruptions of US food SCs was clear in terms of the consumer spending on food as shown in Figure 3 (Mckinsey, 2020). Sales on groceries (e.g., retailers) in March, 2020 were increased by $29 \%$ compared to March, 2019; however, the sales at food services (e.g., restaurants, schools, etc.) dropped by $27 \%$.

\begin{tabular}{l|ccc} 
& \multicolumn{2}{c}{ Grocery } & \multicolumn{2}{c}{ Food service } \\
Mar 2019 & 56.5 & 57.8 \\
\hline & & & 42.2
\end{tabular}

Fig. 3. consumer spending on food in US SCs (Mckinsey, 2020)

Disruption of manufacturing SCs include dropped demand and production stoppage; in particular, for automotive and electronics products. Therefore, manufacturers started to reconsider their operations and switch to open new lines for new products characterized by their essential support to communities. Some of the examples were seen in automotive companies such as Ford that partnered GE health and altered its production to produce ventilators, and 3D printing business, Voodoo manufacturing, delivered medical devices (Vox, 2020). Largely, the emergence and spread of the COVID-19 causing virus over the year 2020 has changed almost every aspect of human life in some way, both work and personal. SCs have faced especially difficult challenges, as the new virus disrupts every step of product and service creation and delivery. COVID19 has changed the way that contributors and decision makers in SCs can interact to make quick decisions to try to keep products available to consumers. While there have been many challenges due to COVID-19, it has also provided lessons for looking into SC aspects to manage and sustain supply and providing opportunities to improve SCs to do what they do best in future. Consequently, based on the abovementioned, the source of this paper inspiration is the informal observation that triggers the general research questions stemming from the behavior of SCs during the pandemic of COVID-19. This consideration has inspired the author to examine a sample of the recent literature to bring insights on the following two research questions:

RQ1. What are the emerging SC aspects in the age of COVID-19?

RQ2. What are the future directions of SC considering the effect of COVID-19?

\section{Research Methodology}

The methodology followed in this paper consist of three steps as shown in Figure 4. First, data is collected, and the search strategy of PRISMA is discussed. Second, the document analytics is conducted by using the shiny app or biblioshiny which is the web-interface of bibliometrics package. Additionally, the data is imported from the SCOPUS database into biblioshiny and then being converted to data frame collection. Third, the raised research questions are addressed accordingly. 


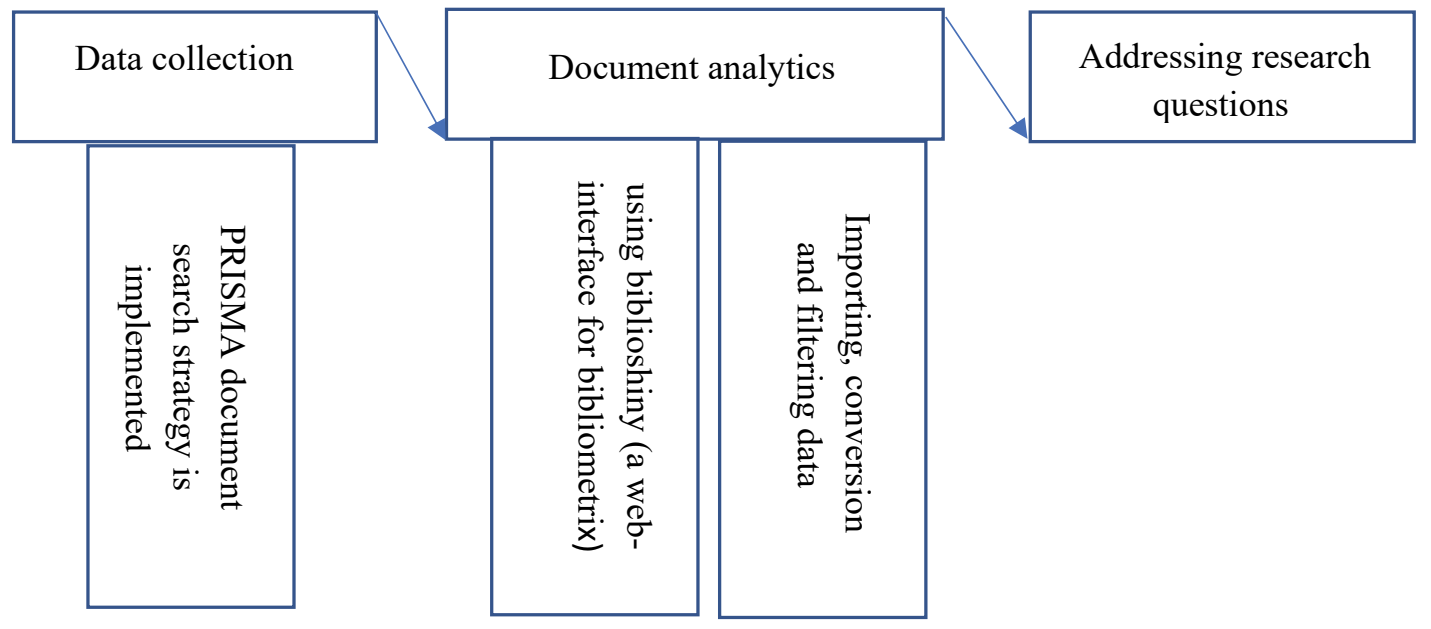

\subsection{Documents search}

Fig. 4. The methodology followed

In this paper, the PRISMA method is used as a strategy of document search that includes a step-wise process in a very explicit and transparent way (Liberati et al., 2009). By adopting this method, keywords are searched, and documents are screened to be included in the analysis or not. PRISMA strategy is shown in figure 5. To understand the impact of Covid19 on supply chains, the search terms "supply chains" OR "supply chain" AND covid-19 OR coronavirus, are used. Also, this paper considers searching in the article title, to fully ensure that the articles mainly contain the keywords searched.

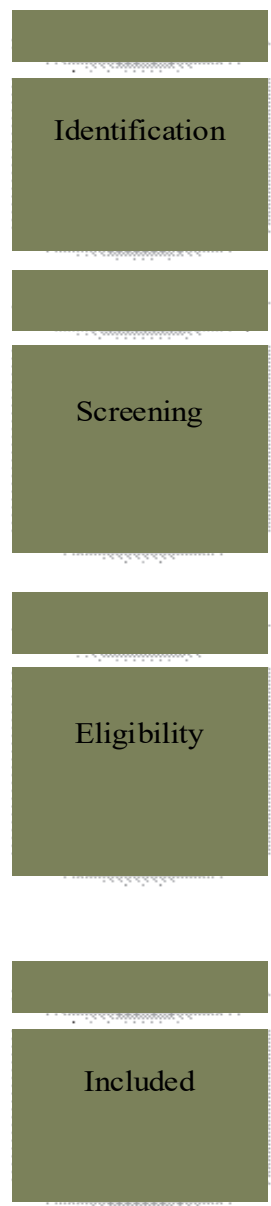

Documents are retrieved by searching key words "supply chains" OR " supply chain" AND covid-19 OR coronavirus using Scopus database including "Article title, Abstract, Keywords" fields, all document types, all languages, all countries, all source titles, all subject areas and all access

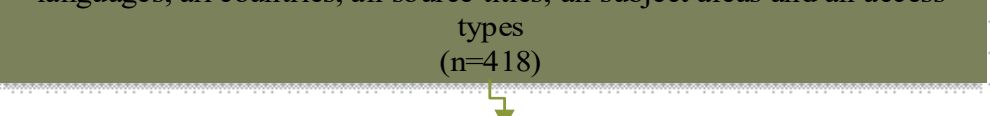

Records excluded due to:

- Non-journal source type such as conference proceedings, book series, book, trade journal, etc.

- Non-English language

- Non-article document type

- Only "article title" field is elligible $(n=318)$

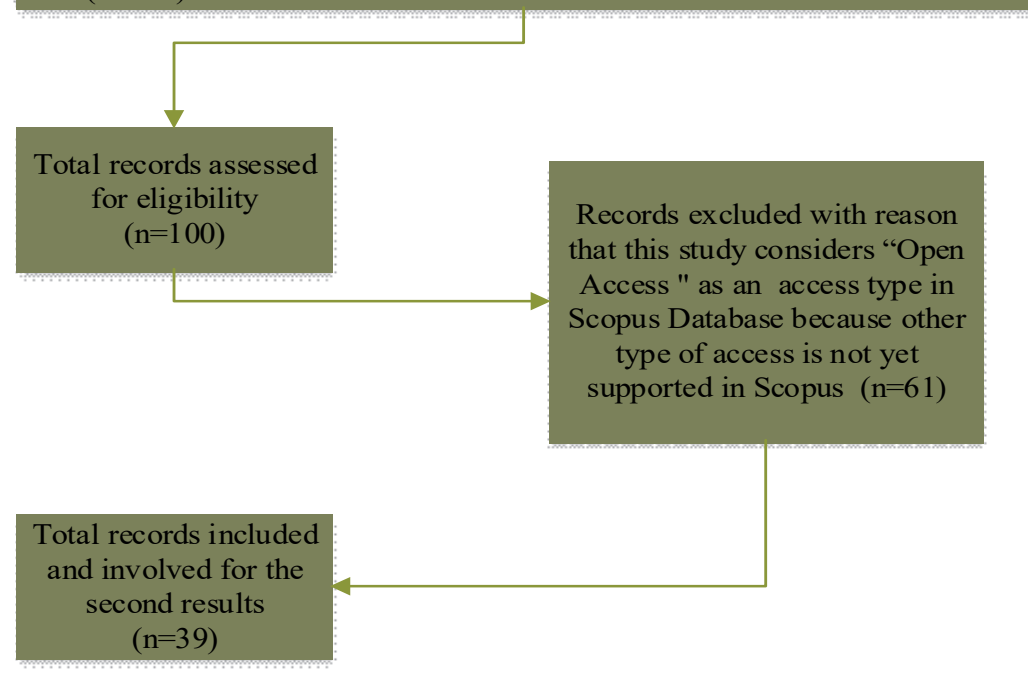

Fig. 5. PRISMA strategy 
In this paper, "bibliometrix" package is a tool proposed by (Aria \& Cuccurullo, 2017) which is more comprehensive than other tools for science mapping analysis such CitNet Explorer (van Eck \& Waltman, 2014), SciMAT (Cobo et al., 2012), CiteSpace (Chen, 2006). R software for statistical computing and graphics is utilized to perform bibliometric analysis. "bibliometrix" package includes the tools for quantitative research for citation and bibliometric analysis. "Biblioshiny" or the shiny app, the web-interface of "bibliometrix", is used for exploring some analysis. Figure 6 shows the steps of getting data to documents analytics. The included data is collected from Scopus database by exporting "BibTex" file. Afterwards, JabRef software is utilized to ensure any duplication. Then, data is loaded to "biblioshiny" and converted into R format in R-studio software. Finally, documents in the file loaded are analyzed and visualized.

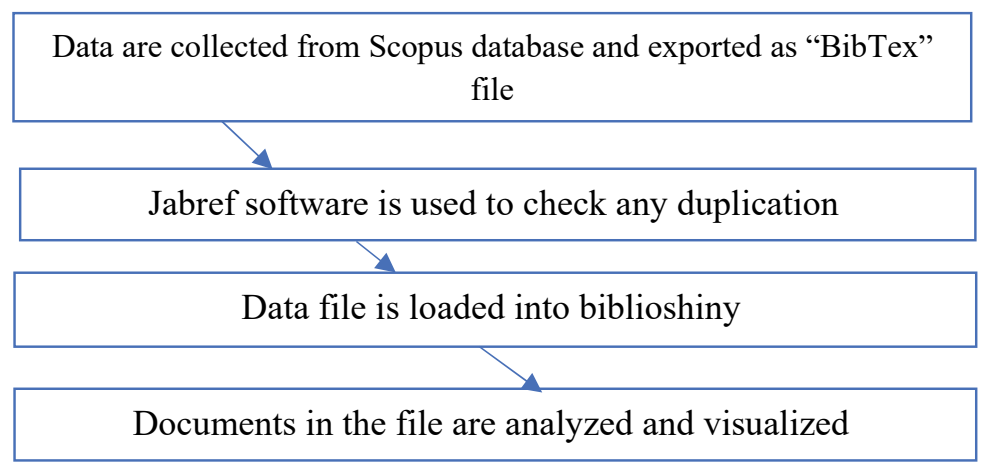

Fig. 6. Steps of data collection to documents analytics

The main information about the included data of 39 articles, resulted when the data file is loaded into "biblioshiny", is provided in Table. The search of documents in the Scopus database is related to the year of 2020. It is found that there are 112 authors in which 6 of them are only single authors of single-authored documents and 2.8 authors per document. The data contains 28 journals (sources), 2159 references and 151 author's keywords.

Table 1

The main information about the included data of 39 articles, resulted when the data file is loaded into "biblioshiny"

\begin{tabular}{cc}
\hline Description & Result \\
\hline Timespan & 2020 \\
Sources (Journal) & 28 \\
Document type (article) & 39 \\
References & 2159 \\
Authors & 112 \\
Authors of single-authored documents & 6 \\
Authors of multi-authored documents & 106 \\
Documents per Author & 0.35 \\
Authors per document & 2.8 \\
Author's keywords & 151 \\
\hline
\end{tabular}

The data is further analyzed to reveal some of the Influential components in terms of the sources, authors, publications, and keywords. Fig. 7 shows the top-10 most influential and relevant sources/journals in which "SUSTAINABILITY" journal has the highest number of documents with 4 articles followed by "APPLIED ECONOMIC PERSPECTIVES AND POLICY" and "IEEE ENGINEERING MANAGEMENT REVIEW" with 3 articles each.

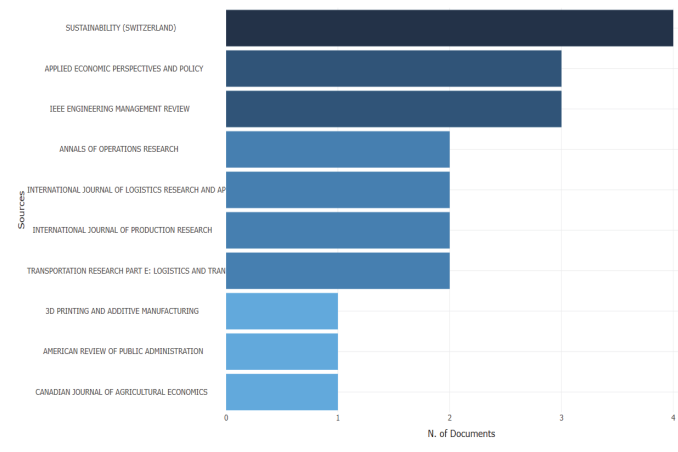

Fig. 7. Top-10 influential sources

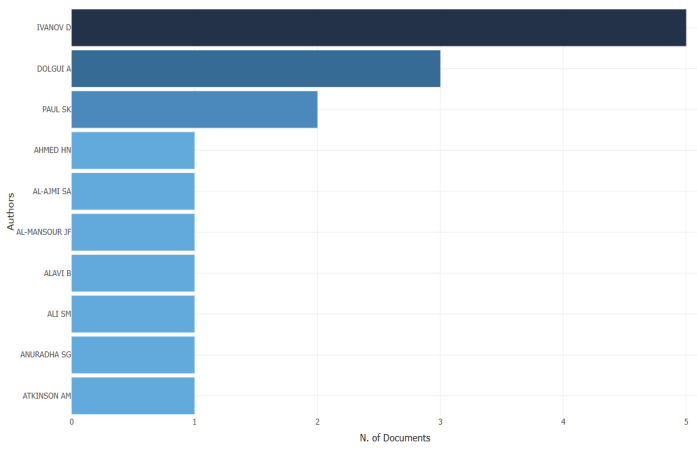

Fig. 8. Top-10 most relevant authors 
Additionally, the influential authors are considered by the most relevant and cited author as shown in Fig. 8 and Fig. 9. The most relevant authors are measured by the greatest number of documents published. The analysis of the data shows that "IVANOV D." is the most influential author that is measured by the highest number of documents published and citations with 5 documents and 182 citations, respectively. "DOLGUI A." is ranked next with 87 citations and 3 documents.

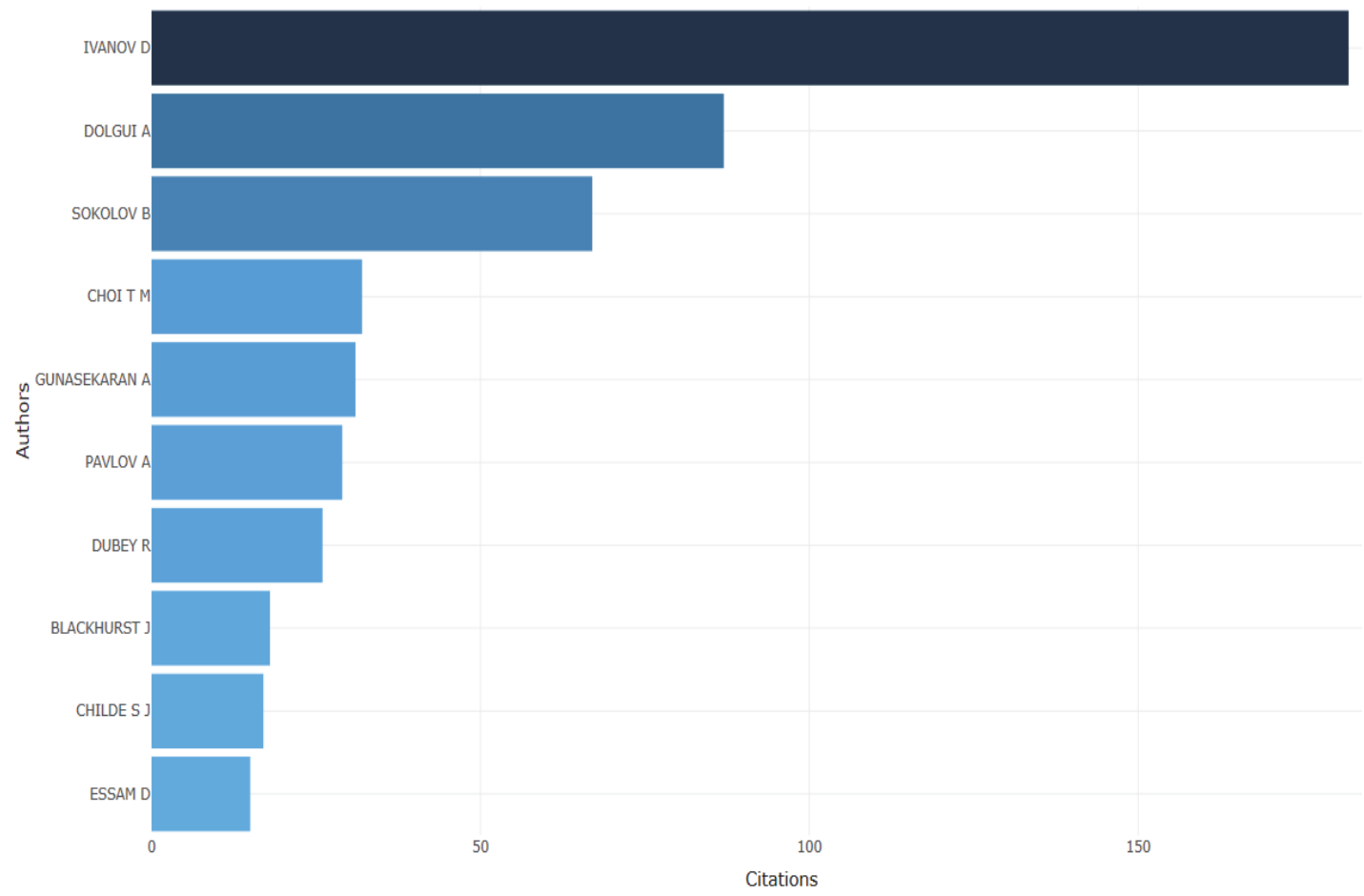

Fig. 9. Top-10 most cited authors

The influential documents are analyzed considering the most local and global citations. The value of Local citations is measured by the frequency that an included document is cited by other authors in the data file. However, the global citations value measures the frequency of an article receiving citations globally. Table shows the 10- most influential documents in which "IVANOV D, 2020, TRANSP RES PART E LOGIST TRANSP REV" has the most frequency of local and global citations with 8 and 134, respectively. "HOBBS JE, 2020, CAN J AGRIC ECON" comes next with 6 local citations and 53 global citations. Table 2 shows the 10- most influential documents in which "IVANOV D, 2020, TRANSP RES PART E LOGIST TRANSP REV" has the most frequency of local and global citations with 8 and 134, respectively.

\section{Table 2}

The most-10 influential documents

\begin{tabular}{ccc}
\hline Document & $\begin{array}{c}\text { Local } \\
\text { Citations }\end{array}$ & $\begin{array}{c}\text { Global } \\
\text { Citations }\end{array}$ \\
\hline IVANOV D, 2020, TRANSP RES PART E LOGIST TRANSP REV & 8 & 134 \\
HOBBS JE, 2020, CAN J AGRIC ECON & 6 & 53 \\
IVANOV D, 2020, INT J PROD RES & 5 & 80 \\
GOVINDAN K, 2020, TRANSP RES PART E LOGIST TRANSP REV & 3 & 23 \\
ZHU G, 2020, SUSTAINABILITY & 2 & 4 \\
QUEIROZ MM, 2020, ANN OPER RES & 2 & 18 \\
PAUL SK, 2020, INT J PHYS DISTRIB LOGIST MANAGE & 2 & 11 \\
IVANOV D, 2020, ANN OPER RES & 2 & 36 \\
CHENARIDES L, 2020, APPL ECON PERSPECT POLICY & 1 & 1 \\
SINGH S, 2020, INT J PROD RES & 1 & 6 \\
\hline
\end{tabular}


Basically, "biblioshiny" offers two fields parameters relating to keywords: "author's keywords" that shows the relevant words mentioned by the authors and "keywords plus" show the most frequent words that are not necessarily mentioned but the authors. "keywords plus" is considered less comprehensive to represent the content of a document (Zhang et al., 2016). Given that to what (Kown, 2018) mentioned about "author's keywords" as the term considered and created by authors, and act as the core elements that characterize the content of the scientific publication. "author's keywords" consist of a list of words that authors consider best represent the content of their article (Aria \& Cuccurullo, 2017). Accordingly, this paper intends to utilize this notion to address the research questions of exploring the emerging issues or trends in supply chains due to the impact or Covid-19 and the future directions. The text data of the authors keywords is represented visually through "Word Cloud" or "Tag Cloud" and "Trend Topics" provided in "biblioshiny" for document analytics. "Word Cloud" typically includes single words in which their significance is displayed with font size or color. It is a very helpful visual representation in recognizing or perceiving the most conspicuous terms when the "author's keywords" field is considered. The word occurrence is measured by its frequency. "Trend Topics" represents the search trends based on the keyword's analysis. Figures 10 and 11 show the "Word Cloud" and "Trend Topics", respectively. They reveal the prominent words or terms that highlight the aspects or issues related to the impact of COVID-19 on supply chains such as sustainability, supply chain disruption, supply chain management, supply chain resilience, viability, and flexibility. As a result, the first research question of exploring the emerging aspect of SCs in the age of COVID-19 will be approached accordingly.

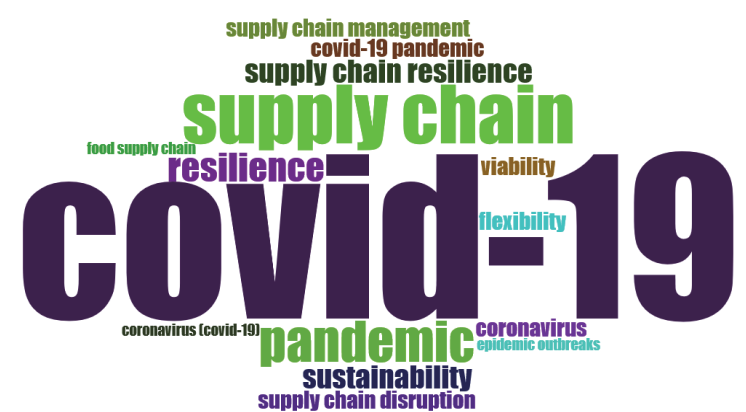

Fig. 10. Word Cloud considering keyword's analysis

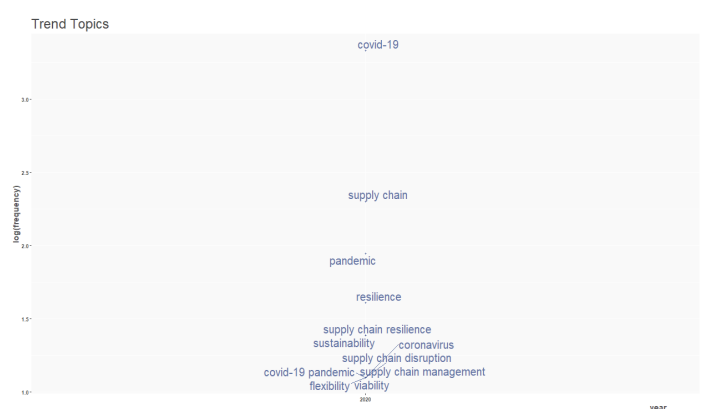

Fig. 11. Trend topics considering keyword's analysis

\section{Addressing Research Questions}

This section focuses on addressing the two research questions about the emerging SC aspects in the age of COVID-19 and the future directions are considering the effect of this pandemic

\subsection{What are the emerging SC aspects in the age of COVID-19?}

\section{SC Disruptions}

SC disruption is defined as "a disruptive event that causes production difficulties for multiple suppliers and in which at least two of these suppliers deliver non-identical goods or services to at least two competing firms" (MacKenzie,2014). The difficulty of SC disruption can be measured by how many members are facing problems with respect to supply or demand of raw materials, component, finished product, services etc. because of an unexpected event (Craighead et al., 2007). Disruption risks such as earthquakes, hurricanes, and attacks might have high effect on operational performances of SCs; however, COVID-19 pandemic is different in terms of the long-term presence of disruptions (Ivanov\& Dolgui,2020b). Basically, the COVID-19 epidemic is the foremost health calamity since the influenza outbreak in the end of World War I, with consequences on public health, financial side, social solidity, political affairs, etc. (Fonseca \& Azevedo, 2020). Every era appears to encounter painful disruptions of normality, but the consequences of the COVID-19 outbreak on commerce were extraordinary (Ketchen \& Craighead, 2020; Veselovská, 2020; Ishida, 2020, Ivanov\& Dolgui,2020a). COVID-19 outbreak has driven global SCs to the edge of collapse (Oh et al., 2020). This epidemic has caused significant uncertainty in all areas of SCs that have witnessed exceptional vulnerabilities in lead times, order sizes, disruptions in network configurations, and critical demand variability (Ivanov\& Dolgui,2020b). COVID-19 has increased the most extensive and damaging SC disruptions in modern history. It also has had serious repercussions for the business types, the majority of which have been adversely impacted to announce severe losses, others have exceptionally boosted their sales volumes during the catastrophe (Al-mansour \& Al-ajmi, 2020). The deadly coronavirus has not only taken the lives of people but also brutally damaged the economy (Singh et al., 2020). Significant stress has been placed by this outbreak on all facets of society including health care, economy, etc. (Atkinson et al., 2020). It is noticeable that this devastating condition perplexes decision makers in industries and governments and upsets community activities and SCs (Govindan et al., 2020), As COVID-19 outbreak worsened, government released orders of that unnecessary business (e.g., food-service industry) to shut down. Despite earlier efforts to build SC resiliency, businesses were unprepared for the massive swings in supply and demand that proliferate across industries all around the world. Coronavirus disease is a massive disaster that has caused serious disruptions across the global SCs, mainly in the medical ones (Govindan, et al 2020). Further, vagueness of the capability of projecting is drawn when this pandemic will be contained despite the coronavirus vaccine promises that we 
are experiencing at the time of writing this paper. Global SCs are disrupted through the delays and terminations of the international logistics, labor force shortages, (Trautrims et al., 2020; Xu et al., 2020). The worldwide propagation of the coronavirus has caused effects such as production disruption of materials and products (e.g., production was compelled to be hold in China, global supply of items was declined), unfulfilled market demand due to delays and obstacles in logistics, growing bankruptcy risk for businesses, and demand instability (Cai \& Luo, 2020). For instance, the demand for products related to preventions of coronavirus such as PPE and ventilators were skyrocketing, whereas some high- tech commodities such as smartphones were falling. The question raised is the survivability of SCs due to the severe inclination of supply and demand in the automotive industry, and the threat of bankruptcy (Ivanov, 2020). Worryingly, automotive, and medical manufacturers are impacted due the shutdown of production facilities in areas affected by COVID-19 (i.e., travel restrictions and unavailability of parts and components has forced Volkswagen to close its automotive facilities in China). The impact extends to cause substantial disruptions in the demand for air travel due to border closures. For instance, food SCs are impacted due to the surge demand for food products (Luckstead et al., 2020). Besides, the demand for smart mobiles and oil-fueled automobiles has been decreased (Cai \& Luo, 2020). Moreover, many of SCs were hurt at the earlier months when the virus had spread all over the planet, leaving people into lockdowns and quarantine, and causing partial or entire shutdown of most important economic sectors (Xu et al., 2020). Due to rigorous lockdowns, and restrictions enacted on producers and retailers, the production and logistics activities have been halted or postponed, in which this influenced the demand and supply of a variety of goods (Singh et al., 2020). COVID-19 mitigation policies geared SCs to encounter unsatisfactory supply availability (Trautrims et al., 2020). As the recent global pandemic has hit SCs, the disruptions have been clear in the challenging for the producers of facing high demand of the most vital items (e.g., toilet paper, face masks, disinfecting spray, hand sanitizer, etc.) (Paul \& Chowdhury, 2020; Ivanov, 2020). Conversely, the supply side has impacted in which raw materials dropped substantially with restrictions of production capability. Given that COVID-19 has created health issues and governments required social distance restrictions on the population, and collecting medical supplies (e.g., ventilators), choosing suitable suppliers to deliver the missing supplies has been challenging, mainly in global SCs, that have shown vulnerability and lack of resilience (Fonseca \& Azevedo, 2020). Strikingly, the SC disruptions have stemmed from the volatility of supply and demand, the core issue of SCs and operations. SCs have faced the consequences by the inability to obtain accurate forecasts due to the high uncertainty of the situation; thus, bullwhip and ripple effects are generated over downstream and upstream (Ivanov and Dolgui 2020a). Even before the serious spread of COVID-19 globally, the disruptions in China produced a ripple effect on the global SCs; however, as the pandemic has dispersed, SCs vulnerabilities have surfaced (Sharma et al., 2020). In such a chaotic situation, companies confronting the epidemic outbreaks have shared concerns such as how long can SCs maintain a disruption and recover after a pandemic (Ivanov, 2020b).

\section{SC Resilience}

Resilience concept is understood as the ability to survive disruptive occurrences and bring operations back to their normal functioning or performance (Ivanov, 2020). The resilience of food SCs is very similar to flexibility which is the ability to react to disruptions to ensure systems' functionality is unimpacted (Chenarides et al., 2020). The challenges started by the disruptions occurred to SCs by COVID-19 when first discovered in China which considered the world's factory (Deloitte 2020). COVID-19 disaster uncovered the vulnerability and weak resilience of the global SCs (Fonseca \& Azevedo, 2020). To that end, the spread of the virus has formed serious ripple effects; therefore, plans must be drawn to bring robust solutions for SC including its resilience (Pournader et al., 2020). The ripple effect is a decisive factor in collapsing and disrupting SC networks due to the demand and supply uncertainty and ineffective forecasting (Ivanov and Das 2020; Ivanov and Dolgui 2020b). Lack of resilience has weakened the decision making process in SCs (Chenarides et al., 2020). In this regard, flexibility or resilience is considered an optimal response, considering firm level, to observed risks such as the COVID-19 crisis (Chenarides et al., 2020). There is an absolute need of reinforcing resilience of SCs of personal protection equipment (PPE) and disinfectants to deal with disruptions provoked by COVID-19 outbreak (Klemes et al., 2020). In managing SCs, Queiroz et al., (2020) and Ivanov\& Dolgui (2020b) highlighted some methods, of the theories of operations research and management on how to examine the SC challenge during the time of COVID-19, such as network and complexity theories, mathematical modeling for advanced analytic or optimization and simulation. These methods are very helpful for SC resilience by measuring the impact of COVID-19 outbreak. Some of the benefits from mathematical optimization include the optimal schedule or sequence to avoid stockout, optimal capacity to meet fluctuating demand, etc. When demand for various points increases and inventories and essential resources need to be allocated, in the case of pandemic such as COVID-19, stochastic optimization models are applied to tackle such problems (Mehrota et al., 2020). Additionally, resilience plans are developed by simulation methods that can provide different scenarios on how to deal with issues resulting (e.g., supply and demand, resources availability, reliability, etc.). decision makers enhance SC resilience by considering not only optimizations methods but also simulations to plan for better responsiveness and forecast disruption scenarios (Currie et al., 2020; Ivanov, 2020a). Simulation models aid in building a resilient and responsive food SC to handle the changing demand to rerouting the vehicles in accordance with travel restrictions in places affected by COVID19 (Singh et al., 2020). Predictive analytics methods are used for forecasting of the demand of goods which in turn helps planning during COVID-19 times (Nikolopoulos et al., 2020). To build solid SC resilience during COVID-19, there is an absolute need for employing technologies and artificial intelligence techniques. For instance, three-dimensional printing (3DP) provided help for hospitals due to the high demand on personal protective equipment and other medical necessities such as face shields and valves for respiratory devices (Larraneta et al., 2020). Also, manufacturing companies who employ 
digital manufacturing and industry 4.0 consideration in their production systems are in a better situation to control ripple effect; hence, building robust and resilient SC networks (Queiroz et al., 2020; Ivanov 2020a, b; Ivanov and Dolgui 2020). Therefore, organizations should invest in industry 4.0 technologies including blockchain technology, big data analytics, etc. due to their capabilities in enhancing SC productivity and visibility (Sharma et al., 2020). To be able to have effective delivery of products and services, in the age of COVID-19, technological involvements are required in SCs (Ray ,2020). Companies should recognize the value of a digital SC key to resilience as it improves the visibility and movement of information (Oh et al., 2020). For example, companies have embraced digital technology to decrease the COVID-19 impact, such as Hersheys and Farmerline who have created digital solutions to support smallholders (Quayson et al., 2020). In fact, as WHO forced measures to fight COVID-19 by minimizing contacts and implementing physical distancing contacting, a huge challenge confronted the SCs that required high percentage of physical contact among labor (e.g., fast-movingconsumer-goods SC) (Kon`car et al., 2020). To abide by such measures, SCs need to invest in digitalization and automation of processes and activities. This will create visibility which is very important to resilience. The importance of such a notion is clear when medical SCs in the USA found some difficulty to endorse effective resilience measures against Covid-19, in the presence of lack of suitable information (Zhu et al., 2020). In other words, suppliers, and manufacturers in SCs will not have a clear insight on what to do amid this situation. Therefore, it will be /*/problematic for healthcare staff, who depend on medical supplies to operate and provide care units, if this issue is not handled properly. Eventually, medical SCs suffer instability and lack o-f resilience.

Given the severe disruptions caused by epidemics, organizations are required to reinforce their SCs resilience to enhance SCs viability (Ivanov \& Dolgui, 2020b). The importance of that resilience perspective should be a guidance to operations and SC management, especially in the times of pandemics to create reactive and dynamic operations (Dolgui et al., 2020). There are four categories and key components of each category in SC resilience in the pandemic outbreak (Queiroz et al., 2020). First, the systems category which is very essential for showing resilience performance including the organization's systems resources and capacities, so it indicates the responsive system. Second, the process category considers logistics and production management. Third, the control category that is very essential and required in operations activities such as inventory and manufacturing control. Fourth, the recovery category that shows how flexible the configuration of SCs is including production, labor availability and transportation networks are. In this regard, coronavirus pandemic has caused many disruptions including the shortages of workers, products, and transportation systems; therefore, the rescue can be quickened by embracing alternative plans such as production restructuring and overproducing of medical supplies to minimize the effect of the outbreak (Queiroz et al., 2020; Ivanov and Dolgui,2020a). For example, in automotive SC resilience, vehicle manufacturers set up their SCs with some backup accommodations, inventory cushions, adaptable capacities to create robust systems and recovery against disruptions caused by pandemics such as Coronavirus that temporarily influences the material flow (Ivanov, 2020b). Another consideration of diversification issue in terms of the number of suppliers in SCs, many of which faced a magnified risk when companies decide to lower costs at the expense of building long-term resilience (Zhu et al., 2020). It has been noticeable that manufacturing flexibility in terms of the product volume and variety, and sourcing diversification, have considerable positive consequences for coping with the shocks of the COVID-19 outbreak to SCs (e.g., the readymade garment SCs) (Taqi et al., 2020). Companies in lean SCs follow costefficient strategies including procurement and sourcing from limited vendors (Shokrani et al., 2020). Also, the Indian pharmaceutical SCs encouraged the single- source reliance in the time of COVID-19 (Pasulurietal. et al., 2020). The question raised in this consideration will be "Is the issue of supplier diversification effective in the times of Coronavirus times?". The answer is clear through the example of the companies who relied on lower-cost outsourcing in China and then their operations were debilitated due to the disruptions caused by COVID-19 including government lockdowns and shutdowns of industrial centers.

The consideration of risk management is very essential for resilient SCs. businesses who pay adequate attention to risk management of their SCs were able to adjust more quickly to restore normality (Zhu et al., 2020). For that, companies can build resilient SC. processes, if they can develop mitigation strategies for the prospective impacts (Xu et al., 2020). COVID19 epidemic is an unknown risk as the likelihood of its occurrence and consequences cannot be accurately forecasted (Kwon, 2020). In fact, COVID-19 outbreak characterizes a SC risk including the impacts of the long-term disruption existence and its irregularity and, concurrent disruptions in supply, demand, and logistics infrastructure. (Ivanov, 2020b). The risk is apparent with the virus existence and the absence of clinical cure including the delay in acquiring the effective vaccine (Singh et al., 2020). COVID-19 pandemic and its mitigation policies have created risks associated with demand, supply, finance, logistics, etc. and it is essential to explore the impact of such risks to build resilient SCs (Sharma et al., 2020). SCs concentrate on identifying and then mitigating the risks coming from the source of disruptions (Handfield et al., 2020). For instance, the response by US health SCs towards COVID-19 risks was ineffective; therefore, the health sector suffered from supply shortages including beds, ventilators, labor, etc. COVID-19 outbreak is considered SC risk, which is uniquely characterized by a long-term disruption presence, disruption spreads such as the ripple effect, and high-level uncertainty (Ivanov, $2020 \mathrm{~b}$ ). The assessment of the impact of COVID-19 is obvious with the harmful implications on businesses and postpone rolling the global economy. COVID-19 epidemic has underlined the vulnerability of SCs, particularly the central European companies, as many of them showed unpreparedness to confront such major disruptions (Veselovská, 2020). Also, COVID-19 has resulted in demand shocks that yielded panic buying by customers. Basically, in the early phases of COVID-19, stores shelves of the important protection supply and food got emptied. This has created pressures on 
specialized SCs in food and other supplies (Hobbs, 2020). In other words, they failed to meet customers' requirements. On the other hand, the supply side was shocked considering the labor shortages and the disturbance to logistical networks due to closures. COVID-19 has had a negative impact on port logistics; therefore, there is a need to have flexible system capacity to absorb the uncertainties and mitigate risks associated (Russel et al., 2020). Basically, the shortages of emergency supply due to the inability to forecast the rise in demand. Additionally, manufacturing capacities were constrained by unavailability of materials and movement restrictions (Ray, 2020). Different strategies are recommended for managing disruptions by the risks and their impacts to restore the normality such as embracing of industry 4.0 technologies, collaboration, and shared accountability (Sharma et al., 2020). The success of emergency preparedness and responsive strategies is highly reliant on identifying risks by comprehensive insight of the impact of COVID-19 on SCs. To successfully manage emergency events like the COVID-19 epidemic and enhance operational performance, considerations such as information technology and collaboration and integrations of systems among SC members are important (Oh et al., 2020). In the cases of demand and supply disruptions, risks can be reduced or avoided through developing recovery models that help modify the production plans to enhance capacity and supply, in which strategies of using emergency sourcing and strong collaboration are developed (Paul \& Chowdhury, 2020). In essence, collaborative strategies by business decision makers and governmental officials to mitigate and survive this disaster (Al-mansour \& Al-ajmi, 2020). Risk management ought to involve emergency plans and strategies to deal with disruptions to SC networks (Hobbs, 2020). Strategies should create collaborative SC between buyers and sellers; hence, trust and information sharing among SC partners would help respond to demand variations. Fig. 4 shows the phases of risk management phases. First, identifying the source of risk in which COVID-19 pandemic enforces challenges on governments to take measures to stop the spread of the virus; therefore, SCs face demand, supply, and financial risks. Second, the impact of risk is assessed through what happened to SCs by the disruptions caused by the virus; in particular, the variations of supply and demand. Finally, responses are developed to mitigate $\mathrm{SC}$ disruptions.

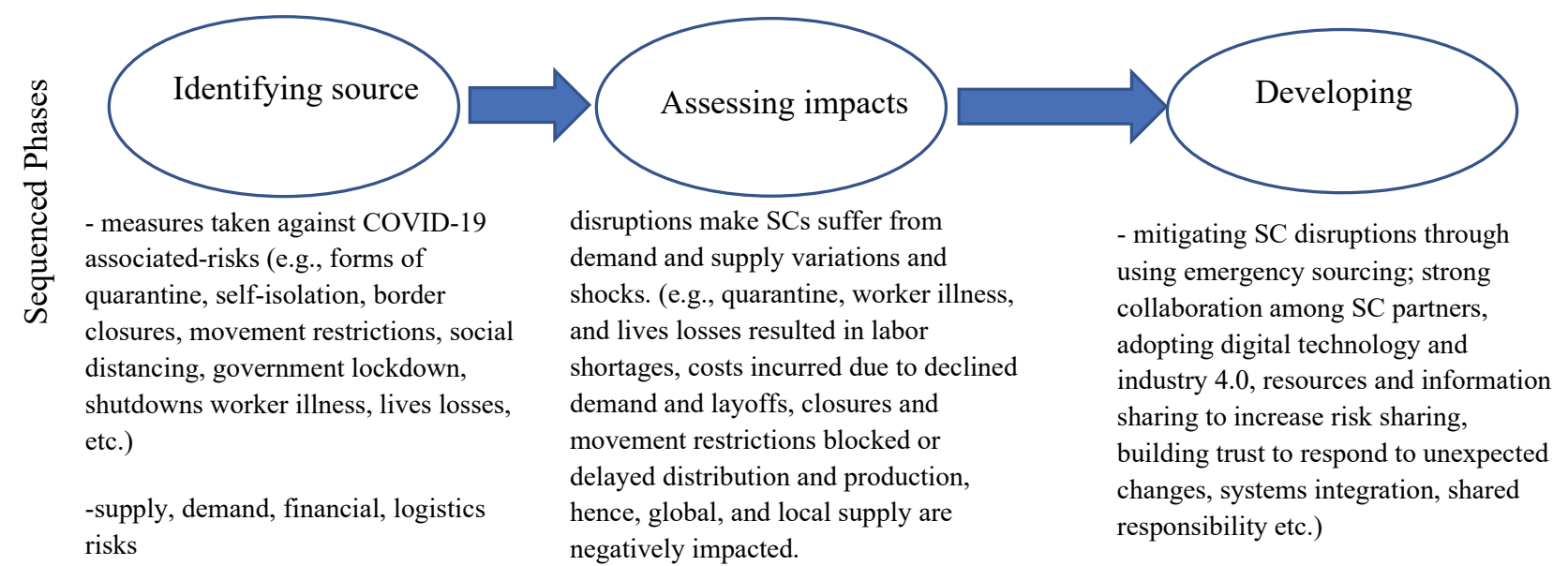

Ketchen \& Craighead, 2020;

Sharma et al., 2020b ;

Hobbs, 2020; Oh et al., 2020; Sharma et al., 2020;

ङ $\quad$ Veselovská, 2020; Ishida, 2020;

Hobbs, 2020; Paul \& Chowdhury, 2020 ;

Paul \& Chowdhury, 2020;

Govindan et al. 2020; Xu et al. 2020;

Ivanov, 2020b; Ray, 2020; Hobbs, 2020; Singh et al., 2020; Sharma Veselovská, 2020; Mehrota et al.,
et al.,2020b; Kwon, 2020; Handfield et $\quad$ 2020; Singh et al., 2020; Ivanov \& al., 2020 Dolgui. 2020b

Hobbs, 2020; Oh et al., 2020; Sharma et al., 2020b;

Xu et al., 2020; Taqi et al., 2020;

Fig. 12. Risk management phases

To that end, building resiliency of SC is very important to grant the ability for businesses to recover from COVID-19 event, that negatively affects the SCs. Therefore, there is a need for various considerations, to build required resiliency including its key components, such as risk management, supplier diversification, digitalization and OR theories as shown in Fig. 13. 


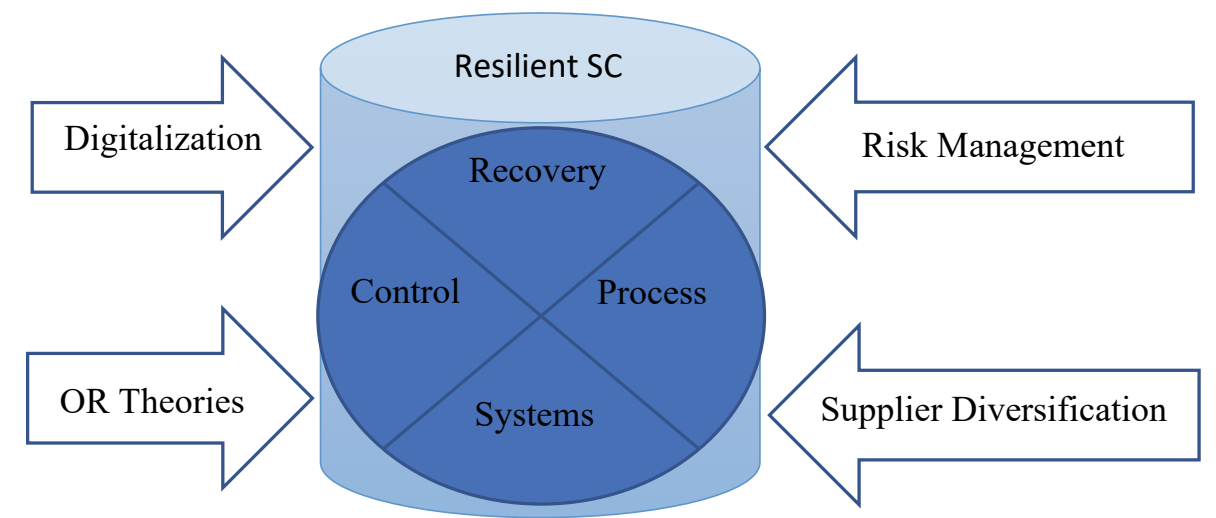

Fig. 13. Considerations for SC resilience

\section{SC Viability}

Viability is the system capacity that meets the requirements of surviving in a shifting environment; hence, SC viability is characterized by the ability to resist the exceptional disruptions by COVID-19 to ensure survivability for a long period of time (Ivanov \& Dolgui 2020a). There is a strategic perspective, when SC viability is considered, in terms of flexible SC network designs for meeting objectives of matching supply and demand (Ivanov, 2020b). In essence, SC viability requires resilience that ensures multiple feedback cycles, so it guarantees survivability of SCs in future. It is found that resilient SCs tolerate negative occurrences, such as disruptions, and recover; However, when they can maintain themselves and survive at a long-term perspective in transforming the environment, SCs are considered viable (Ivanov, 2020). Fundamentally, in the times of COVID-19, SC viability is measured by the capability of delivering goods and services for marketplaces and societies at a long period of time and on a broader scale. For instance, the intertwined supply network (ISN), that was introduced by (Ivanov \& Dolgui, 2020b), offers goods and services, to societies and markets, which are needed to guarantee a long-term survival such as electronics ISNs that offer long-term communication in markets and societies. Basically, SCs have become viable to help survivability or sustainability to resist the longstanding of COVID-19 outbreak on the worldwide economics (Sharma et al., 2020). In the challenge of such a pandemic, it is very essential to investigate SC redesign methods for structural shifts in supply and demand (e.g., vendors economic failure, changes in market demand). This has driven the necessity to explore the concept of SC viability as an aspect for achieving survivability considering the changing environmental and structural requirements in the long run (Ivanov \& Dolgui, 2020b). SC viability is not only about its performance (i.e., profits or costs), it also relates to the behavioral transformations of systems that are dynamically structured or designed; However, resiliency is considered as a disruption-driven perspective (Sharma et al., 2020).

\section{SC Sustainability}

Companies have tried to prioritize economic sustainability during the shocking COVID-19; therefore, their survival is clearly threatened (Trautrims et al., 2020). Sustainable SCs is related to the survivability including economic (e.g., market), social (e.g., community standards, employee practices, etc.), and environmental (e.g., waste management, recycling, efficiency, etc.) considerations (Sharma et al., 2020). Severe global disruptions influence all parts of SC ecosystems (i.e., society, nature, and economy) (Ivanov, 2020). Additionally, SCs viability is considered as a factor to enhance the survivability of SCs; hence, sustainability is built. In other words, viability balances SC systems to achieve economic, social, environmental objectives in the course of shifting environments such as what have caused by COVID-19 epidemic (Sharma et al., 2020) As SC resilience requires digital perspectives of the business processes to ensure recoveries, the effective implementation of implementation of the Internet of Things concept for connecting and integrating systems to ultimately reach the sustainability of the SCs (e.g., fast-moving-consumer-goods SCs) during and after the coronavirus outbreak (Koncar et al., 2020). In essence, one of the major issues considering SC sustainability is waste management reduction (e.g., PPE reusability); however, energy consumption has been reduced due to minimize production, transportation, and other social activities (Klemes et al., 2020). The problem of maintaining SC sustainability is more on the side of the smallmedium enterprises, many of which lack the flexibility to sustain supply in the times of the recent pandemic (Kon car et al., 2020). Pertaining to SC management, successful businesses target sustainability by concentrating on how to enhance their processes resilience and speeding up the end-to-end digital transformation (Fonseca \& Azevedo, 2020).

\section{SC Management}

The major challenge for SC management is handling unplanned events such as COVID-19 (Oh et al., 2020). The results of government lockdowns, travelling and public gathering bans have adversely impacted businesses and the issue of managing their SCs (Ketchen \& Craighead, 2020. For instance, the consequences were clear on the inability of restaurants to serve their customers through their main in-house dining channel. Additionally, the problems associated with acquiring related suppliers of food ingredients. Consequently, businesses (e.g., restaurants) have begun to look for ways to reach out their customers through changing their business models to stay competitive by adding entrepreneurship and strategic 
management issues (Ketchen \& Craighead, 2020). In the entrepreneurship way, Omni-channel consideration is adopted to enable better customer experience through the integration of goods, information, purchases, and refunds (Song, Wang, Liu, \& Li, 2020, Pasuluri et al., 2020). Moreover, during COVID-19 pandemic, with stay-home orders or lowering service hours of operations, businesses found themselves forced to depend more on the online-distribution channel. This has exerted financial pressures on the last-mile delivery strategy. For instance, Unilever who resorted to Terra Drone (a Japanese startup) to utilize the service of drones to perform last-mile delivery of Ben and Jerry's ice cream (Kan, 2020). Another growth issue in SC management is that automotive industries are shifting toward centralized management in the event of coronavirus pandemic (Ishida, 2020). This will raise a question of "Is globalization perspective of SCs being a weakness in the age of COVID-19?. To provide an answer to such a question, the international trade has been decelerated due borders closures during COVID-19 (Quayson et al, 2020). COVID-19 crisis has revealed the fragility and exposed the global SCs' vulnerability and low resilience. For instance, the current status of the global SC connections makes it problematic for smallholder farmers to sell their harvests. The concern of managing changing SCs by escalating the domestic sourcing (e.g., India is considered one of the largest pharmaceutical exporters but still import the main materials from China) (Pasuluri et al., 2020). Further, the Indian industry considered this epidemic as a wake-up call to recognize the necessity to depend on its own local sourcing and minimize reliance on China (Sharma et al., 2020). During COVID-19, local and regional food systems enterprises made responsive twists to new market channels and buyers by enhancing relationships in local SCs (Thilmany et al., 2020). For that, globalization has made SCs of many businesses become explicitly susceptible to the coronavirus epidemic (Ivanov, 2020).

Due to the expansion of globalization, enterprises are more linked and more easily shaken by swift environmental shifts (Oh et al., 2020). Also, many companies were unable to take effective measures to manage the inactive distribution of their products and services and severe deterioration in sales. Therefore, demand uncertainty and rigorous competition push companies to find new ways to improve responsiveness and value of SC management, and accelerate their strategies' formulations to restructure or redesign their SC now and after COVID-19. For instance, given the impact of COVID-19 (e.g., shutdowns due to quarantined labors) on downstream part of food SCs, the upper stream was managed by pursuing operations of agricultural production and labors are considered essential (Luckstead et al., 2020) The management side is needed for all aspects of SC. Therefore, lack of resilience is argued to cause less market collapse than a lack of the management (Chenarides et al., 2020). Also, this outbreak proves long-term SC management to be a greater riskmanagement strategy than traditional ones (Trautrims et al., 2020). To impact SC management positively, companies need to create more resilient SCs to be able to build successful viable and sustainable SCs (Fonseca \& Azevedo, 2020). To put pieces together, given COVID-19 epidemic is expected to have long term consequences on SCs, successful management of $\mathrm{SC}$ requires considering the different aspects including resilience, viability, and sustainability as shown in Fig. 14. To react against SCs disruptions caused by the unprecedented epidemic, the short-term perspective is concerned of building resilient SCs to enhance operational and tactical performances. However, the long-term perspective is related to the strategic building of viable and sustainable SCs. Resilient SC acts as an input to ensure the transformation into viable SC, which is eventually needed to obtain sustainable SC. Profoundly, this paper attempts to provide more insights to SCs decision makers on how to deal with current and post circumstances of COVID-19.

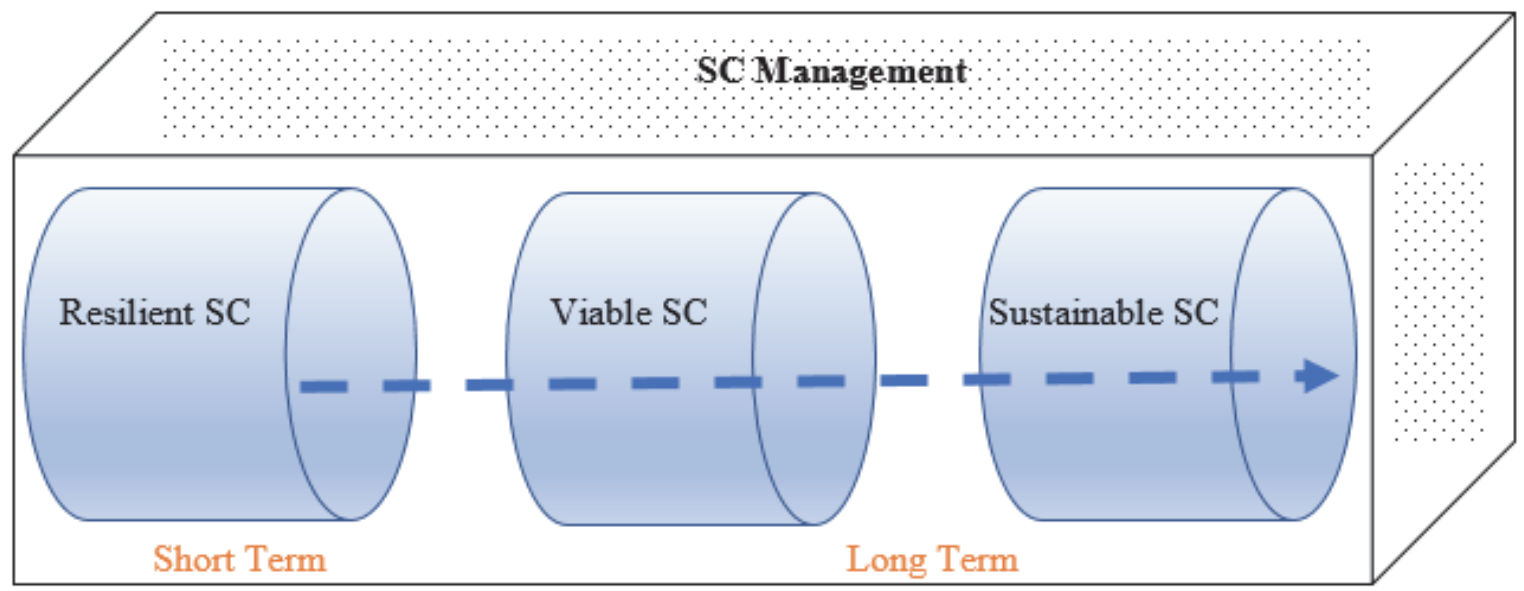

Fig. 14. SC aspects' relationship

\subsection{What Are the Future Directions of SC Considering the Effect of COVID-19}

It is highly believed that COVID-19 pandemic isthe most major shock that global and local SCs have faced. The COVID 19pandemic has caused a lot of challenges for companies to efficiently run andkeep up with the new age of the industry. Some companies are unable to keep upwith these challenges and are being forced to shut down. Therefore, it is prudentto consider the future directions of SC based on the impact of COVID-19outbreak. 
As China is considered as the world's factory and the key global supplier to many countries, the increased demand, due to the coronavirus, on some essential supplies has created supply problems. For instance, China, in the early stages of the virus, minimized its export of personal protective equipment (PPE) to Korea that highly depend on the Chinese production; consequently, this has caused severe shortage on such supplies (Oh et al., 2020). Reliance on a single supplier is very risky in the times of COVID-19 pandemic; therefore, risk can be reduced or avoided by sourcing diversification (Zhu et al., 2020; Taqi et al., 2020; Shokrani et al., 2020; Pasulurietal. et al., 2020).

Further, global SC has shown their weakness as global trade has been slowed down due to closures and bans among countries (Quayson et al., 2020). This will pave the way to the necessity for domestic sourcing (Pasuluri et al., 2020). Basically, Food SCs sourcing from non-global suppliers is less risky (Hobbs, 2020)

Now and Towards the Future, Industries Will Focus on Digitalization to Improve Real-Time Visibility and Robust Decisions

The end of coronavirus has not been guaranteed so far, therefore, acceleration of digital and automated SC solutions can cure SCs in the future. These solutions will allow businesses to be more transparent with each other and show a track record of success. When companies develop a shared information system (e.g., inventory), they acquire real-time inventory data from their SC members instantaneously; hence decision making is improved (Oh et al., 2020). For effective delivery processes, during and after the pandemic high-tech engagements are essential for enhancing the visibility and information (Ray, 2020; Oh et al., 2020). Fundamentally, Industry 4.0 including computerization, automation, robotics, and advancedmanufacturing technologies, will be crucial for SC success. For example, 3DP is utilized to meet demand for essential supplies during the pandemic (Larraneta et al., 2020). Also, digital manufacturing is employed to control ripple effect; thus, SCs can be managed well (Queiroz et al., 2020; Ivanov 2020a, b; Ivanov and Dolgui, 2020a). Industry 4.0 technologies enhances SC productivity and visibility (Sharma et al., 2020).

\section{Holding Inventory or Safety Stock as Opposed to Just-in-Time Replenishment in SCs}

As the future's focus will be on a better design for SC resilience, companies will be less resilient when considering Just-inTime strategy with no thought for safety stock. In any potential outbreak, other than the current epidemic, SCs will be more responsive through implementing plans of guaranteeing more safety stock in their distribution pipelines (Pasuluri, et al, 2020). In this regard, inventory control is a very important activity to ensure resilience (Queiroz et al., 2020). Also, inventory cushions or safety stock have been rescuing some shortage situations from the pandemic disruptions (Ivanov, 2020).

\section{Managing SCs for High Resilience}

SCs have long focused on improving efficiency and lowering costs, but COVID-19 has renewed focus on another key factor, resilience. It is certain that resilience will perform a primary role promising viability of the SCs of the future (Ivanov, 2020). SC managers need to act fast with implemented necessary changes to supply diversity and technology to put an end to SC breakdowns and make SCs more resilient to similar events in the future. They also need to ensure robust systems against any disruption; in particular, the resilience of food SCs (Chenarides et al., 2020). As a matter of fact, calling for high SC resilience will ensure keeping risk management on track by developing effective mitigation strategies (Xu et al., 2020). This future direction will not only help large companies to benefit from resiliency against any potential disruption, but also will benefit SMEs (Blackhurst et al., 2011).

\section{More Investment in and Reliance on Operations Research and Business Analytics}

Companies today need to capitalize on data during this pandemic time and generate business analytics to better understand past performances and forecast future trends. Operations research and analytics include effective tools such as optimization and simulation are very helpful for building SC resilience, and they are used when any business challenges emerge (Queiroz et al., 2020; Ivanov\& Dolgui,2020b). The future of COVID-19 pandemic is still uncertain; therefore, stochastic optimization techniques are required to deal with problems associated with production, scheduling, demand, etc. (Mehrota et al., 2020). Given that the core of SC management is to match supply with demand, decision makers implement predictive analytics to effectively forecast market demand to plan for required capacity (Nikolopoulos et al., 2020). More insight and prescription are captured, by operation research and business analytics, on other important issues for SC such as supplier selection, vehicle routing problem, SC network design and logistical problems.

\section{Companies will rethink their food SCs}

Before this virus hit our world, food SCs focused on obtaining, manufacturing, and supplying their product at reduced costs. As COVID-19 has emerged and shown defenselessness within food SCs, in which this will be inevitable in future times. With the border closings by governments, the export and import of food supplies are hampered (Sharma et al., 2020). COVID-19 epidemic will have long-lasting impacts on the environment of food SCs including the rise of the online-grocery 
supply (Hobbs, 2020). Further, the stay-home orders, reductions, and layoffs of unimportant labor, due to costs incurred, has disrupted food SCs (Luckstead et al., 2020). Therefore, huge pressures are enforced on working labor in such conditions and managing and designing the downstream and upstream of food SCs. Basically, the vulnerabilities of food SCs was apparent through the inabilities for meeting the variable demands, and this resulted in low -SC resilience. Consequently, it is necessary to apply efficient furcating methods such as simulation to gain responsiveness and robust food SCs in future (Singh et al., 2020). Also, the motivations for behaviors such as panic buying and its implications for food SCs should be well-understood and examined as this signals something very underlying and major for SCs' future (Hobbs, 2020). To that end, this has raised the need for companies to rethink their food SCs.

\section{Conclusions}

As we all have expected, many challenges have risen out of the COVID-19 pandemic. This pandemic has not only affected health and public safety, but also has a huge impact on industries in the business world. Consequently, SC systems and global production have been heavily disrupted due to the recent coronavirus outbreak. Most SC managers and policymakers have been attempting to develop new strategies and plans for restoring production patterns to satisfy consumer demand. Thus, this paper has received the motivation to examine the literature related to address two research questions about the emerging SC aspects in the age of COVID-19 and the future directions are considering the effect of this pandemic. To address the research questions, this paper provides methodology that consists of including three steps. First, PRISMA strategy for document search is applied as documents are retrieved from SCOPUS citation database. strategy of is discussed. Second, the sample of documents is analyzed using "biblioshiny", the web-interface of "bibliometrix" package in R software for statistical computing and graphics, is used for exploring some analysis. Third, the research questions are answered accordingly. The sample selected includes 39 articles, and some of the bibliometric analysis related to main information, influential authors, influential documents, influential sources, and influential keywords, are explored. Fundamentally, the influential keywords in this paper, including the author keywords that best represent the article's content, show the prominent terms considering "Word Cloud" and "Trend Topics" offered by "biblioshiny" for document analytics. The results showed that the most important terms pertaining to SCs include SC disruptions, SC management, SC resilience, viability, and flexibility. This has paved the way towards answering the first research question in which aspects of SC disruptions, SC resilience, SC viability, SC sustainability, and SC management, are addressed. Hence, it is included that resilient SCs are built to be recovered from the disruptions caused by COVID-19 in the short-term perspective. As COVID19 has shown that we need more resilient SCs, viable SC can be created in the long-term perspective, which ultimately builds sustainable SC accordingly. As a result, these considerations facilitate successful SC management. Further, the important future directions are explored to include companies will consider the transformation from globalization to regionalization, industries will focus on digitalization to improve real-time visibility and robust decisions holding inventory or safety stock as opposed to just-in-time replenishment in SCs, the need for managing SCs for high resilience, more investment in and reliance on operations research and business analytics and companies will rethink their food SCs. The main contributions of this paper are as follows. First, it provides more insights, to the literature body, about how the main aspects of supply chain are addressed in the times of COVID-19 outbreak. Second, it explores the SC future directions that can act as a support for SC decision makers. The provided research agenda is very beneficial for scholars and practitioners to gain more understanding about the impact of COVID-19 pandemic on SCs. More insightful research can be studied in the future such as investigating the impact of labor shortages, digitalization, etc., due to COVID-19 pandemic, on SC performance.

\section{References}

Alhawari, O. I., Süer, G. A., \& Bhutta, M. K. S. (2020). Operations Performance Considering Demand Coverage Scenarios for Individual Products and Products Families in Supply Chains. International Journal of Production Economics, 108012 .

Alhawari, O., \& Süer, G. (2019). Optimal Number of Cells for a Part Family in a Stochastic Demand Environment. Procedia Manufacturing, 38, 299-306.

Al-Mansour, J. F., \& Al-Ajmi, S. A. (2020). Coronavirus' COVID-19'-Supply Chain Disruption and Implications for Strategy, Economy, and Management. The Journal of Asian Finance, Economics, and Business, 7(9), $659-672$.

Aria, M., \& Cuccurullo, C. (2017). bibliometrix: An R-tool for comprehensive science mapping analysis. Journal of informetrics, 11(4), 959-975.

Atkinson, C. L., McCue, C., Prier, E., \& Atkinson, A. M. (2020). Supply Chain Manipulation, Misrepresentation, and Magical Thinking During the COVID-19 Pandemic. The American Review of Public Administration, 50(6-7), 628-634.

Ayati, N., Saiyarsarai, P., \& Nikfar, S. (2020). Short and long-term impacts of COVID-19 on the pharmaceutical sector. DARU Journal of Pharmaceutical Sciences, 1-7.

Beamon, B. . (1998). Supply chain design and analysis: models and methods. International Journal of Production Economics, 55, 281-94.

Cai, M., \& Luo, J. (2020). Influence of COVID-19 on Manufacturing Industry and Corresponding Countermeasures from Supply Chain Perspective. Journal of Shanghai Jiaotong University (Science), 25(4), 409-416 
Chen, C. (2006). CiteSpace II: Detecting and visualizing emerging trends and transient patterns in scientific literature. Journal of the American Society for information Science and Technology, 57(3), 359-377.

Chenarides, L., Manfredo, M., \& Richards, T. J. (2020). COVID-19 and Food Supply Chains. Applied Economic Perspectives and Policy.

Choi, T.-M., Wen X., Sun X., Chung S.-H. (2019). The mean-variance approach for global supply chain risk analysis with air logistics in the blockchain technology era. Transportation Res. Part E: Logistics Transportation Rev.; 127:178-191

Cobo, M. J., López-Herrera, A. G., Herrera-Viedma, E., \& Herrera, F. (2012). SciMAT: A new science mapping analysis software tool. Journal of the American Society for Information Science and Technology, 63(8), 1609-1630.

Craighead, C.W., Blackhurst, J., Rungtusanatham, M.J. and Handfield, R.B. (2007) The severity of supply chain disruptions: Design characteristics and mitigation capabilities. Decision Sciences, 38(1), 131-156

Dolgui A., Ivanov D., Rozhkov M. (2020). Does the ripple effect influence the bullwhip effect? An integrated analysis of structural and operational dynamics in the supply chain. International Journal of Proect Research, 58(5), $1285-1301$.

Erenay, B. (2016). Concurrent Supply Chain Network \& Manufacturing Systems Design Under Uncertain Parameters. Ohio University. Retrieved from https://etd.ohiolink.edu/!etd.send file?accession=ohiou1459206318\&disposition=inline

Fonseca, L. M., \& Azevedo, A. L. (2020). COVID-19: outcomes for Global Supply Chains. Management \& Marketing. Challenges for the Knowledge Society, 15(s1), 424-438.

Ganeshan, R., Jack, E., Magazine, M. J., \& Stephens, P. (1999). A taxonomic review of supply chain management research. In Quantitative models for supply chain management (pp. 839-879). Springer, Boston, MA

Govindan, K., Mina, H., \& Alavi, B. (2020). A decision support system for demand management in healthcare supply chains considering the epidemic outbreaks: A case study of coronavirus disease 2019 (COVID-19). Transportation Research Part E: Logistics and Transportation Review, 138, 101967.

Handfield, R., Finkenstadt, D. J., Schneller, E. S., Godfrey, A. B., \& Guinto, P. (2020). A Commons for a Supply Chain in the Post-COVID-19 Era: The Case for a Reformed Strategic National Stockpile. The Milbank Quarterly, 98(4), 10581090 .

Hobbs, J. E. (2020). Food supply chains during the COVID-19 pandemic. Canadian Journal of Agricultural Economics/Revue canadienne d'agroeconomie, 68(2), 171-176.

Ishida, S. (2020). Perspectives on supply chain management in a pandemic and the post-COVID-19 era. IEEE Engineering Management Review, 48(3), 146-152.

Ivanov, D. (2020a). Predicting the impacts of epidemic outbreaks on global supply chains: A simulation-based analysis on the coronavirus outbreak (COVID-19/SARS-CoV-2) case. Transportation Research Part E: Logistics and Transportation Review, 136, 101922.

Ivanov, D. (2020b). Viable supply chain model: integrating agility, resilience and sustainability perspectives-lessons from and thinking beyond the COVID-19 pandemic. Annals of Operations Research, 1.

Ivanov, D., \& Dolgui, A. (2020a). Viability of intertwined supply networks: extending the supply chain resilience angles towards survivability. A position paper motivated by COVID-19 outbreak. International Journal of Production Research, 58(10), 2904-2915

Ivanov, D., \& Dolgui, A. (2020b). OR-methods for coping with the ripple effect in supply chains during COVID-19 pandemic: Managerial insights and research implications. International Journal of Production Economics, 107921.

Ivanov, D., Dolgui, A., Das, A., \& Sokolov, B. (2019). Digital supply chain twins: Managing the ripple effect, resilience, and disruption risks by data-driven optimization, simulation, and visibility. In Handbook of ripple effects in the supply chain (pp. 309-332). Springer, Cham.

Ketchen Jr, D. J., \& Craighead, C. W. (2020). Research at the Intersection of Entrepreneurship, Supply Chain Management, and Strategic Management: Opportunities Highlighted by COVID-19. Journal of Management, 46(8), 1330-1341.

Kinra, A., Ivanov, D., Das, A., \& Dolgui, A. (2020). Ripple effect quantification by supplier risk exposure assessment. International Journal of Production Research, 58(18), 5559-5578.

Klemeš, J. J., Van Fan, Y., \& Jiang, P. (2020). The energy and environmental footprints of COVID-19 fighting measuresPPE, disinfection, supply chains. Energy, 211, 118701.

Klibi, W., Martel, A., \& Guitouni, A. (2010). The design of robust value-creating supply chain networks : A critical review. European Journal of Operational Research, 203(2), 283-293.

Končar, J., Grubor, A., Marić, R., Vučenović, S., \& Vukmirović, G. (2020). Setbacks to IoT implementation in the function of FMCG supply chain sustainability during COVID-19 pandemic. Sustainability, 12(18), 7391

Kumar, A., Luthra, S., Mangla, S. K., \& Kazançoğlu, Y. (2020). COVID-19 impact on sustainable production and operations management. Sustainable Operations and Computers, 1, 1-7.

Kwon, O. K. (2020). How is the COVID-19 pandemic affecting global supply chains, logistics, and transportation? Journal of International Logistics and Trade, 18(3), 107-111.

Lambiase, A., Mastrocinque, E., \& Miranda, S. (2013). Strategic planning and design of supply chains: a literature review. International Journal of Engineering Business Management, 5, 1-11.

Larrañeta, E., Dominguez-Robles, J., \& Lamprou, D. A. (2020). Additive Manufacturing Can Assist in the Fight Against COVID-19 and Other Pandemics and Impact on the Global Supply Chain. 3D Printing and Additive Manufacturing.

Lee, H. L., \& Billington, C. (1995). The evolution of supply-chain-management models and practice at HewlettPackard. Interfaces, 25(5), 42-63.

Li, Y., \& Zobel, C. W. (2020). Exploring supply chain network resilience in the presence of the ripple effect. International 
Journal of Production Economics, 107693

Liberati, A., Altman, D. G., Tetzlaff, J., Mulrow, C., Gøtzsche, P. C., Ioannidis, J. P. A., ... Moher, D. (2009). The PRISMA statement for reporting systematic reviews and meta-analysis of studies that evaluate health care interventions: explanation and elaboration. Italian Journal of Public Health, 6(4).

Linton, T., Vakil, B., 2020. Coronavirus is proving we need more resilient supply chains. Harward business review, March 5, 2020, https://hbr.org/2020/03/coronavirus-is-proving-that-we-need-more-resilient-supply-chains, accessed on November 15, 2020.

Luckstead, J., Nayga Jr, R. M., \& Snell, H. A. (2020). Labor Issues in the Food Supply Chain Amid the COVID-19 Pandemic. Applied Economic Perspectives and Policy.

MacKenzie, C. A., Barker, K., \& Santos, J. R. (2014). Modeling a severe supply chain disruption and post-disaster decision making with application to the Japanese earthquake and tsunami. IIE Transactions, 46(12), 1243-1260.

Mehrotra, S., Rahimian, H., Barah, M., Luo, F., \& Schantz, K. (2020). A model of supply-chain decisions for resource sharing with an application to ventilator allocation to combat COVID-19. Naval Research Logistics (NRL).

Meixell, M. J., \& Gargeya, V. B. (2005). Global supply chain design: A literature review and critique. Transportation Research, 41, 531-550.

Nikolopoulos, K., Punia, S., Schäfers, A., Tsinopoulos, C., \& Vasilakis, C. (2020). Forecasting and planning during a pandemic: COVID-19 growth rates, supply chain disruptions, and governmental decisions. European Journal of Operational Research.

Oh, S., Moon, H. C., \& Zhong, Y. (2020). Contingency Management and Supply Chain Performance in Korea: A COVID19 Pandemic Approach. Sustainability, 12(23), 9823.

Pasuluri, B. S., Anuradha, S. G., Manga, J., \& Karanam, D. (2020). Post COVID-19 potentials and innovation: The future supply chain. International Journal of Research in Pharmaceutical Sciences, 1054-1057.

Paul, S. K., \& Chowdhury, P. (2020). A production recovery plan in manufacturing supply chains for a high-demand item during COVID-19. International Journal of Physical Distribution \& Logistics Management.

Quayson, M., Bai, C., \& Osei, V. (2020). Digital inclusion for resilient post-COVID-19 supply chains: smallholder farmer perspectives. IEEE Engineering Management Review, 48(3), 104-110.

Ray, A. (2020). Managing supply chain aspects of the COVID-19 pandemic in India. Indian Chemical Engineer, 1-6.

Russell, D., Ruamsook, K., \& Roso, V. (2020). Managing supply chain uncertainty by building flexibility in container port capacity: a logistics triad perspective and the COVID-19 case. Maritime Economics \& Logistics, 1-22.

Sharma, A., Gupta, P., \& Jha, R. (2020). COVID-19: Impact on Health Supply Chain and Lessons to Be Learnt. Journal of Health Management, 22(2), 248-261

Sharma, M., Luthra, S., Joshi, S., \& Kumar, A. (2020). Developing a framework for enhancing survivability of sustainable supply chains during and post-COVID-19 pandemic. International Journal of Logistics Research and Applications, 121.

Sharma, R., Shishodia, A., Kamble, S., Gunasekaran, A., \& Belhadi, A. (2020). Agriculture supply chain risks and COVID19: mitigation strategies and implications for the practitioners. International Journal of Logistics Research and Applications, 1-27.

Siegel, P. B. (2005). Managing agricultural production risk: Innovations in developing countries. Commodity Risk Management Group, Agricultural and Rural Development Department. World Bank Report No. 32727. Washington D.C.

Singh, S., Kumar, R., Panchal, R., \& Tiwari, M. K. (2020). Impact of COVID-19 on logistics systems and disruptions in food supply chain. International Journal of Production Research, 1-16.

Shokrani, A., Loukaides, E. G., Elias, E., \& Lunt, A. J. (2020). Exploration of alternative supply chains and distributed manufacturing in response to COVID-19; a case study of medical face shields. Materials \& design, 192, 108749.

Stevenson, J. W. (2018). Operations Management. (13th Ed.). New York, NY: McGraw-Hill Education.

Taqi, H. M., Ahmed, H. N., Paul, S., Garshasbi, M., Ali, S. M., Kabir, G., \& Paul, S. K. (2020). Strategies to manage the impacts of the COVID-19 pandemic in the supply chain: implications for improving economic and social sustainability. Sustainability, 12(22), 9483.

Thilmany, D., Canales, E., Low, S. A., \& Boys, K. Local Food Supply Chain Dynamics and Resilience during COVID19. Applied Economic Perspectives and Policy.

Title of subordinate document. In: US food supply chain: Disruptions and implications from COVIDhttps://www.mckinsey.com/industries/consumer-packaged-goods/our-insights/us-food-supply-chain-disruptions-andimplications-from-covid-19\#. Accessed October 2020.

Title of subordinate document. In Factories that used to make perfume, T-shirts, and cars are now making supplies to fight the coronavirus. https:/www.vox.com/the-goods/2020/4/6/21207135/factories-face-masks-ventilators-hand-sanitizercoronavirus-manufacturing. Accessed October 2020.

Trautrims, A., Schleper, M. C., Cakir, M. S., \& Gold, S. (2020). Survival at the expense of the weakest? Managing modern slavery risks in supply chains during COVID-19. Journal of Risk Research, 1-6.

Van Eck, N. J., \& Waltman, L. (2014). Visualizing bibliometric networks. In Measuring scholarly impact (pp. 285-320). Springer, Cham.

Van der Vorst, J. G. A. J., \& Beulens, A. J. M. (2002). Identifying sources of uncertainty to generate supply chain redesign strategies. International Journal of Physical Distribution \& Logistics Management, 32(6), 409-430.

Veselovská, L. (2020). Supply chain disruptions in the context of early stages of the global COVID-19 outbreak. Problems 
and Perspectives in Management, 18(2), 490.

Wisner, J. D. (2016). Operations Management: A Supply Chain Process Approach (1st Ed.)

$\mathrm{Xu}, \mathrm{Z}$., Elomri, A., Kerbache, L., \& El Omri, A. (2020). Impacts of COVID-19 on Global Supply Chains: Facts and Perspectives. IEEE Engineering Management Review, 48(3), 153-166.

Zhang, J., Yu, Q., Zheng, F., Long, C., Lu, Z., \& Duan, Z. (2016). Comparing keywords plus of WOS and author keywords: A case study of patient adherence research. Journal of the Association for Information Science and Technology, 67(4), 967-972.

Zsidisin, G. A. (2003). A Grounded Definition of Supply Risk. Journal of Purchasing and Supply Management, 9, 217224.

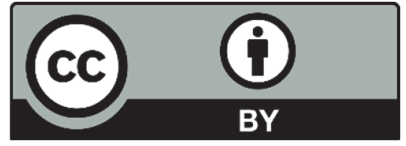

(C) 2021 by the authors; licensee Growing Science, Canada. This is an open access article distributed under the terms and conditions of the Creative Commons Attribution (CC-BY) license (http://creativecommons.org/licenses/by/4.0/). 